\title{
Prevalence of Myofascial Trigger Points and Diagnostic Criteria of Different Muscles in Function of the Medial Longitudinal Arch
}

\author{
Juan C. Zuil-Escobar, PT, MSc, ${ }^{\text {a }}$ Carmen B. Martínez-Cepa, PT, PhD, ${ }^{a}$ \\ Jose A. Martín-Urrialde, PT, PhD, ${ }^{a}$ Antonia Gómez-Conesa, PT, $\mathrm{PhD}^{\mathrm{b}}$
}

From the ${ }^{a}$ Department of Nursing and Physical Therapy, Faculty of Medicine, Centro de Estudios Universitarios (CEU)-San Pablo University, San Pablo, Madrid; and ${ }^{b}$ Department of Physical Therapy, Faculty of Medicine, University of Murcia, Murcia, Spain.

\begin{abstract}
Objectives: To evaluate the reliability of the used diagnostic criteria of latent trigger points (LTrPs) and pressure pain thresholds and to evaluate the prevalence of LTrPs in several muscles of the lower limb in subjects with a lower medial longitudinal arch (MLA) compared with controls. Design: Cross-sectional study.

Setting: University campus.

Participants: Subjects with a lower limb MLA $(n=82)$ and controls $(n=82)(N=164)$.

Interventions: Not applicable.

Main Outcome Measures: The navicular drop test was used to classify subjects with a lower MLA ( $\geq 10 \mathrm{~mm})$ and controls (5-9mm). The Simons et al recommended specific diagnostic criteria and pressure pain thresholds were used to evaluate the prevalence of LTrPs in several muscles of the lower limb, which was compared between the 2 groups. The reliability was evaluated using Cohen's kappa and intraclass correlation coefficient. The unpaired Student $t$ test and chi-square test were used to evaluate the difference in the LTrP prevalence between the 2 groups.

Results: The intrarater reliability of the navicular drop test and the diagnosis of LTrPs was excellent, with the taut band and tender spot being the most reliable diagnostic criteria. In the lower MLA group, 60 subjects $(73 \%)$ presented at least $1 \mathrm{LTrP}$ whereas 57 controls (70\%) presented at least 1 LTrP. The lower MLA group showed more LTrPs $(4.46 \pm 4.10)$ than did controls $(3.32 \pm 3.24)(P<.05)$. There were significantly $(P<.05)$ more subjects with LTrPs in the flexor digitorum longus, tibialis anterior, and vastus medialis in the lower MLA group than in the control group. Conclusions: LTrPs are common in the lower limb muscles in both controls and subjects with a lower MLA. A lower MLA is associated with a higher prevalence of LTrPs, which are significant in the flexor digitorum longus, tibialis anterior, and vastus medialis.

Archives of Physical Medicine and Rehabilitation 2015;96:1123-30
\end{abstract}

(C) 2015 by the American Congress of Rehabilitation Medicine

The medial longitudinal arch (MLA) of the foot has important functions during both bipedal standing and gait, participating in the impact absorption and transmission of ground reaction forces. ${ }^{1}$ The MLA presents large differences between individuals and could affect the foot functions. ${ }^{2}$

Changes in the height of the MLA can affect other structures. A lower MLA is associated with subtalar pronation, whereas a higher MLA is associated with subtalar supination. ${ }^{3}$ A lower MLA and subtalar pronation are related to several alignments of the lower limb, especially in the weight-bearing position. Several

Disclosure: none. authors have suggested that a lower MLA and foot pronation are associated with tibial internal rotation, ${ }^{4}$ decreased external tibial torsion, ${ }^{5}$ anterior knee laxity, ${ }^{6,7}$ greater genu recurvatum, ${ }^{5}$ or increased pelvis anteversion. ${ }^{8}$ These alignments could create knee rotation stress ${ }^{9}$ and increase lateral patellofemoral joint stress. ${ }^{10}$ In fact, the height of the MLA is considered as a relevant factor for lower limb injuries, ${ }^{11}$ so both high and low MLAs may increase the risk of injuries. ${ }^{12}$ An excessive navicular drop test (NDT) $(>10 \mathrm{~mm})$ is associated with tibial stress syndrome s.14 $^{13,14}$ and patellofemoral pain syndrome. ${ }^{10,15,16}$ Thus, subjects with NDT $>10 \mathrm{~mm}$ were 3.4 times more likely to develop patellofemoral pain syndrome than were subjects with an NDT of $4 \mathrm{~mm} .{ }^{16}$ Subjects with an anterior noncontact cruciate ligament injury 
present a high NDT. ${ }^{17,18}$ Hertel et al ${ }^{19}$ showed that subjects with NDT $>8 \mathrm{~mm}$ were 20 times more likely to have sustained an anterior cruciate ligament injury than were subjects with NDT $<6.3 \mathrm{~mm}$. Subjects with medial knee osteoarthritis also present foot pronation ${ }^{20}$ and a high NDT than do controls. ${ }^{21}$ In addition, a relationship between the height of the MLA and low back pain has been suggested. ${ }^{22}$

The height of the MLA can affect several functions, including postural stability, ${ }^{23}$ plantar pressure distribution, ${ }^{24}$ and muscle activity. ${ }^{25}$ A lower MLA is probably associated with changes in muscle function in the lower limb. Two studies showed that subjects with flat and pronated feet show greater electromyographic activity of the invertor muscles and lower activity of the evertor muscles, ${ }^{26}$ and this type of foot may affect the muscle activity of the vastus medialis (VM), vastus lateralis, and biceps femoris. ${ }^{27}$ An NDT $>8 \mathrm{~mm}$ affects the neuromuscular response of quadriceps, hamstrings, and gastrocnemius during weight-bearing perturbations. ${ }^{28}$ An NDT $\geq 13 \mathrm{~mm}$ decreases concentric plantar flexion strength in subjects with a lower MLA compared with controls. ${ }^{29}$ It has been suggested that a lower MLA needs an additional muscular support during gait $^{30}$ and this could explain muscle fatigue and dysfunction.

A myofascial trigger point (MTrP) is defined as a hyperirritable focus in a muscle taut band that is painful on compression, stretching, or overloading the muscle. ${ }^{31}$ An MTrP can be classified as active (ATrP) or latent (LTrP). ATrPs can spontaneously trigger local and referred pain, motor dysfunction, autonomic phenomena, and local twitch response (LTR) when they are correctly stimulated. ${ }^{32}$ An LTrP does not cause spontaneous pain; however, pain and other symptoms can be induced by needle stimulation or manually, ${ }^{33}$ although the response in the latter case is lower. ${ }^{32}$

Both ATrPs and LTrPs are common in patients with myofascial pain syndrome. ${ }^{34,35}$ LTrPs are also present in subjects without pain. The prevalence of LTrPs in the shoulder girdle muscles has been studied by several authors. Sola et $\mathrm{al}^{36}$ found $\geq 1$ LTrPs in $41 \%$ of the 200 asymptomatic subjects studied. Lucas et $\mathrm{al}^{37}$ observed that almost $90 \%$ of the 154 uninjured subjects studied presented at least $1 \mathrm{LTrP}$. Regarding the lower limb, Grieve et $\mathrm{al}^{38}$ found a prevalence of $13 \%$ to $30 \%$ of LTrPs in the gastrocnemius and soleus in healthy subjects.

LTrPs present biomechanical alterations, ${ }^{39,40}$ spontaneous electrical activity, ${ }^{41-43}$ and changes in the ultrasound image. ${ }^{44}$ Although LTrPs are considered minor injury, they decrease strength, ${ }^{31}$ affect reciprocal inhibition, ${ }^{42}$ produce muscle cramps, ${ }^{40}$ and restriction of the range of movement. ${ }^{43}$ In addition, LTrPs affected the muscle activation patterns, showing more

\begin{tabular}{|l|}
\hline List of abbreviations: \\
ATrP active trigger point \\
FDL flexor digitorum longus \\
ICC intraclass correlation coefficient \\
LTR local twitch response \\
LTrP latent trigger point \\
MLA medial longitudinal arch \\
MTrP myofascial trigger point \\
NDT navicular drop test \\
PB peroneus brevis \\
PL peroneus longus \\
PPT pressure pain threshold \\
TA tibialis anterior \\
TP tibialis posterior \\
VM vastus medialis \\
\hline
\end{tabular}

variability in these patterns and decreasing the movement efficiency. $^{45}$

Several factors are related to the development of MTrPs, including changes in normal alignment and posture. ${ }^{31}$ A lower MLA is considered a factor of activation and perpetuation of several MTrPs, including VM, peroneus longus (PL), peroneus brevis (PB), tibialis posterior (TP), and flexor digitorum longus (FDL) ${ }^{46}$ However, there are no studies that evaluated the relation between a lower MLA and MTrPs (both ATrPs and LTrPs).

LTrPs can affect muscle function and can easily turn into ATrPs; therefore, it is necessary to evaluate their prevalence. There are no studies that evaluated the prevalence of LTrPs in subjects with a lower MLA compared with controls. The objectives of this study were to evaluate the intrarater reliability of the NDT and the specific diagnostic criteria of LTrPs and to evaluate the prevalence of LTrPs in several muscles of the lower limb in subjects with a lower MLA compared with controls.

\section{Methods}

A cross-sectional study was conducted to evaluate the prevalence of LTrPs in several muscles of the lower limb in subjects with a lower MLA compared with controls. Previously, an internal pilot study $(n=40)$ was conducted to calculate the sample size and to study the intrarater reliability of the procedures used in the principal study. To calculate the sample size, the mean prevalence of LTrPs that can be affected by a lower MLA was used. The prevalence was $20 \%$ in the control group $(n=20$; mean age, $23.3 \pm 3.6 y ; 12$ women and 8 men) and $40 \%$ in the lower MLA group ( $n=20$; mean age, $23.8 \pm 4.4 y ; 13$ women and 7 men). The ENE program (version 3.0) ${ }^{\mathrm{a}}$ was used, with a precision level of $5 \%$ and $80 \%$ power. The sample size was 82 subjects per group. The intrarater reliability was calculated using a test-retest study. The examination was done by an experienced physical therapist, with a gap of 48 hours between evaluations. Subjects and rater were blinded to the examination results.

The study included volunteers without pain in response to a poster campaign. All of them were informed of the objectives and about the procedure and completed a consent form before being included in the study. The project observed the principles outlined in the Declaration of Helsinki of 1975 and was approved by the Research Ethics Committee of the Centro de Estudios Universitarios San Pablo University. Inclusion criteria include an $\mathrm{NDT} \geq 10 \mathrm{~mm}$ in the lower MLA group and an NDT ranging from 5 to $9 \mathrm{~mm}^{23,47,48}$ in the control group. To avoid other factors that could be related to the prevalence of LTrPs, the following exclusion criteria were established: undergone lower extremity surgery, suffered from acute injuries, presented lower limb deformities, suffered from systemic or neurological diseases that could affect pain perception, and presented a reduced normal range of movement in the lower limb. Participants who met these criteria were excluded, although they were asymptomatic. Lower limb dominance was determined using the kicking ball test. ${ }^{49}$ Age, sex, and body mass index were documented. In the control group, 48 women $(59 \%)$ and 34 men $(41 \%)$ were included, whereas in the lower MLA group, 44 women (54\%) and 38 men (36\%) were included. No statistically significant differences were found in demographic variables between groups. Table 1 summarizes the participants' characteristics.

A modification of the Brody process ${ }^{50}$ was used to evaluate the NDT (fig 1): the tester marked the navicular tuberosity using a washable marker, with the subject standing barefoot on the floor. 
The medial and lateral aspects of the talar dome were palpated with the index finger over the anteromedial portion of the talar dome and the thumb over the sinus talus. The foot was slowly everted and inverted until the talus was in a central position, and the depressions felt under both fingers were equal. The distance between the navicular tuberosity and the floor was measured (in millimeters), with the subtalar joint in the neutral position. Later, the height of the navicular tuberosity was measured again in the relaxed stance. The NDT was the difference between the 2 measurements. ${ }^{50}$ The procedure was repeated 3 times, and the average value was recorded.

The prevalence of LTrPs was evaluated as described by Simons et $\mathrm{al}^{46}$ using palpation techniques on the following muscles: gastrocnemius (MTrP1 and MTrP2), soleus (MTrP1), PL, PB, tibialis anterior (TA), extensor digitorum longus, FDL, and rectus femoris, VM (MTrP1 and MTrP2), and vastus lateralis of the quadriceps (MTrP1 and MTrP2). The following procedures were used: (1) flat palpation on the quadriceps (VM, vastus lateralis, and rectus femoris), TA, extensor digitorum longus, PL, and PB, with subjects in the supine position; (2) flat palpation on the FDL, with patients lying on their sides; (3) pincer palpation on the gastrocnemius (fig 2), with subjects lying on their sides; (4) pincer palpation of the soleus, with subjects lying on their sides and knee flexed.

The order for evaluating MTrPs was randomized for each subject.

The criteria recommended by Simons et $\mathrm{al}^{31}$ were used to diagnose LTrPs: (1) a palpable taut band in skeletal muscle; (2) a hypersensitive tender spot; (3) reproduction of referred pain of the MTrP in response to compression; (4) jump sign; (5) LTR provoked by snapping palpation of the taut band.

The LTrP was considered positive if $\geq 2$ criteria recommended by Grieve $^{38}$ were met.

To confirm LTrP diagnosis, the pressure pain threshold (PPT) (in $\mathrm{kg} / \mathrm{cm}^{2}$ ) was evaluated on LTrP sites. The PPT, defined as the minimum pressure that induces pain or discomfort, ${ }^{51}$ was evaluated using an analogical algometer (FDK 20). ${ }^{\mathrm{b}}$ First, the point of maximum tenderness was located with the finger. Then, the tip of the algometer was applied perpendicularly to the skin surface, with the pressure being continuously increased at a rate of $1 \mathrm{~kg} / \mathrm{s}$. Subjects were asked to report when they felt pain or discomfort. ${ }^{51}$ There was a 30-second interval between each of the 3 measurements being carried out, with the mean used to calculate the PPT. ${ }^{37}$

LTrPs and the NDT were evaluated by a physical therapist with more than 15 years of experience in the management of the myofascial pain syndrome and 6 years of experience in the use of the NDT. The NDT was performed before the examination of LTrPs so as to blind the rater.

Table 1 Participants' characteristics

\begin{tabular}{llll}
\hline Characteristic & $\begin{array}{l}\text { Control Group } \\
(\mathrm{n}=82)\end{array}$ & $\begin{array}{l}\text { Lower MLA Group } \\
(\mathrm{n}=82)\end{array}$ & $P$ \\
\hline Age $(\mathrm{y})$ & $22.842 \pm 3.898$ & $23.597 \pm 5.329$ & .313 \\
$\begin{array}{l}\text { Body mass } \\
\quad \text { index }\left(\mathrm{kg} / \mathrm{m}^{2}\right)\end{array}$ & $23.916 \pm 1.720$ & $24.507 \pm 1.967$ & .134 \\
\hline
\end{tabular}

NOTE. Values are mean \pm SD.

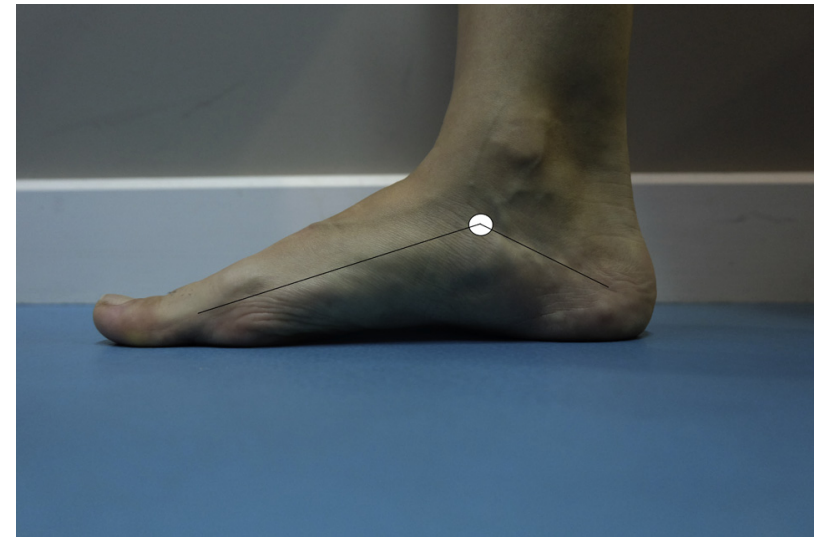

Fig 1 Navicular drop test. The circle indicates the navicular tuberosity.

\section{Statistical analysis}

The normal distribution of the quantitative variables was assessed using the Kolmogorov-Smirnov test; in this case, parametric tests were performed. Descriptive analysis was performed using frequencies and percentages for qualitative variables and means and SDs for quantitative variables. The intrarater reliability of the diagnosis of LTrPs was evaluated using Cohen's kappa, and the intraclass correlation coefficient (ICC) was used to evaluate the NDT and PPT. The kappa value, a measure of the intrarater reliability, was interpreted as follows: 0 to .39 , poor; .40 to .74 , moderate; $\geq .75$, excellent. ${ }^{52}$

The unpaired Student $t$ test was performed to analyze the differences in quantitative demographic variables and the number of LTrPs between both groups. The chi-square test was performed to evaluate the difference in qualitative demographic variables and the prevalence of LTrPs in each muscle between both groups. An alpha level of .05 was used for all the tests performed. Statistical analysis was performed using SPSS version $20^{\circ}$ by an author blinded to the measurements.

\section{Results}

\section{Reliability of the measurements}

The intrarater reliability of the NDT was excellent in both groups, with an ICC value being .935 (95\% confidence interval, .853-.972)

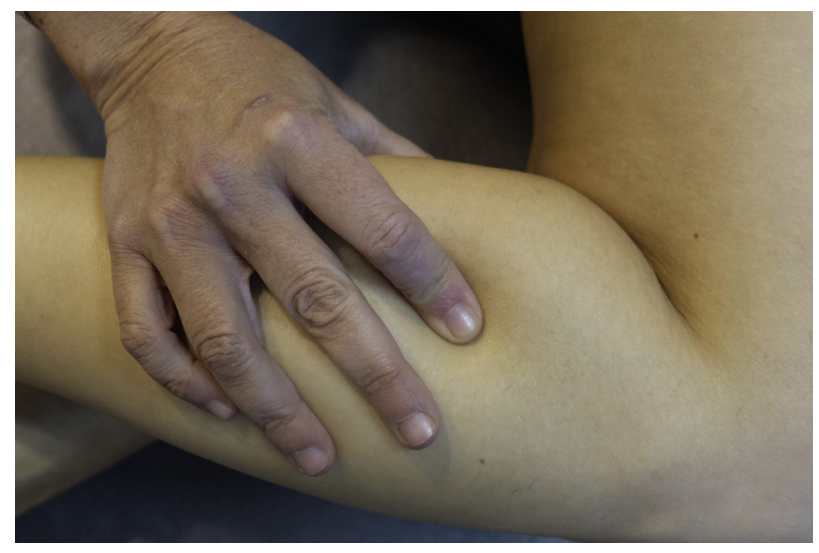

Fig 2 Identification of the MTrP in the lateral gastrocnemius. 
Table 2 Cohen's kappa for the diagnostic criteria of LTrPs and ICC (95\% confidence interval) for the PPT ( $\left.\mathrm{kg} / \mathrm{cm}^{2}\right)$ in the lower MLA group

\begin{tabular}{lllllll}
\hline Muscle & Taut Band & Tender Spot & Jump Sign & Referred Pain & LTrP & PPT \\
\hline Gastrocnemius MTrP1 & 1 & 1 & 0.828 & 1 & 1 & $.903(.772-.960)$ \\
Gastrocnemius MTrP2 & 1 & 0.828 & 1 & 0.773 & 0.857 & $.844(.648-.935)$ \\
Soleus MTrP1 & 0.857 & 0.773 & 0.857 & 1 & 1 & $.856(.636-.943)$ \\
PL MTrP & 0.857 & 0.857 & 1 & 0.857 & 1 & $.923(.806-.970)$ \\
PB MTrP & 0.773 & 1 & 1 & 0.773 & 0.857 & $.848(.616-.940)$ \\
Extensor digitorum longus MTrP & 0.875 & 0.875 & 1 & 0.875 & 0.875 & $.907(.766-.963)$ \\
TA MTrP & 1 & 0.857 & 0.773 & 1 & 1 & $.893(.750-.956)$ \\
FDL MTrP & 1 & 1 & 0.875 & 1 & 0.875 & $.891(.725-.957)$ \\
Rectus femoris MTrP & 0.875 & 1 & 0.643 & 1 & 1 & $.838(.635-.932)$ \\
VM MTrP1 & 1 & 1 & 0.875 & 1 & 1 & $.883(.728-.952)$ \\
VM MTrP2 & 0.894 & 1 & 0.857 & 0.857 & 1 & $.864(.689-.944)$ \\
Vastus lateralis MTrP1 & 1 & 1 & 0.875 & 1 & .975 \\
Vastus lateralis MTrP2 & 1 & 0.828 & 0.773 & 1 & $.921(.854-.942)$ \\
\hline
\end{tabular}

in the control group and .925 (95\% confidence interval, .821-.970) in the lower MLA group.

The reliability of the diagnosis of LTrPs was excellent in both the control group (Cohen's $\kappa=0.773-1$ ) and the lower MLA group (Cohen's $\kappa=0.828-1$ ). With regard to the specific diagnostic criteria, excellent intrarater reliability was found in both groups, except for the jump sign in the rectus femoris LTrP (both groups), gastrocnemius LTrP1 (control group), and soleus LTrP1 (control group). The reliability of the LTR was not calculated, because it was absent in most muscles. Tables 2 and 3 list Cohen's kappa and ICC values.

\section{Prevalence of LTrPs}

Fifty-seven subjects of the control group (70\%) presented at least 1 LTrP in the muscles evaluated. In the lower MLA group, 60 subjects $(73 \%)$ presented at least 1 LTrP. The lower MLA group showed more LTrPs $(4.46 \pm 4.10)$ than did the control group $(3.32 \pm 3.24)$, and the difference was statistically significant $(P<.05)$.

The prevalence of each LTrP (fig 3 ) and the specific diagnosis criteria are presented in table 4 . There were significantly $(P<.05)$ more subjects with LTrPs in the FDL, TA, and VM (both LTrP1 and LTrP2) in the lower MLA group than in the control group.

\section{Discussion}

\section{Reliability of the measurements}

In the present study, the NDT showed excellent intrarater reliability. Other studies showed similar results in both healthy ${ }^{10,16,28}$ and injured subjects. ${ }^{10,16}$ The reliability of the diagnosis of LTrPs was excellent in all the muscles evaluated, which was $>.820$ in all of them, with the exception of the soleus (control group). The taut band and tender spot showed excellent reliability, whereas the jump sign was the least reliable diagnostic criterion. The LTR was absent in several of the muscles evaluated. Previously, the LTR was found in the medial gastrocnemius in only $1 \%$ of the sample $(n=220){ }^{38}$ This criterion was the most difficult to elicit by palpation, ${ }^{31}$ and it was the least reliable in the shoulder muscles. ${ }^{53}$ The reliability of the PPT was excellent $(\mathrm{ICCs}=.824-.926)$. The intrarater reliability of the PPT in LTrPs has been studied in the shoulder muscles, which have shown similar results. ${ }^{37}$

\section{Prevalence of LTrPs}

The principal objective of the present study was to evaluate whether there is a significant difference in the prevalence of LTrPs in the lower limb muscles between subjects with a lower MLA and

Table 3 Cohen's kappa for the diagnostic criteria of LTrPs and ICC (95\% confidence interval) for the PPT ( $\left.\mathrm{kg} / \mathrm{cm}^{2}\right)$ in the control group

\begin{tabular}{|c|c|c|c|c|c|c|}
\hline Muscle & Taut Band & Tender Spot & Jump Sign & Referred Pain & $\mathrm{LTrP}$ & PPT \\
\hline Gastrocnemius MTrP1 & 1 & 1 & 0.643 & 0.828 & 1 & $.864(.656-.946)$ \\
\hline Gastrocnemius MTrP2 & 1 & 1 & 1 & 1 & 1 & $.918(.804-.967)$ \\
\hline Soleus MTrP1 & 1 & 1 & 0.647 & 0.773 & 0.773 & $.867(.665-.947)$ \\
\hline PL MTrP & 1 & 1 & 0.875 & 1 & 1 & $.923(.806-.970)$ \\
\hline PB MTrP & 0.773 & 1 & 1 & 0.773 & 0.857 & $.926(.812-.971)$ \\
\hline Extensor digitorum longus $\mathrm{MTr} P$ & 1 & 1 & 0.898 & 0.857 & 0.898 & $.869(.700-.946)$ \\
\hline TA MTrP & 1 & 0.857 & 0.773 & 1 & 1 & $.893(.750-.956)$ \\
\hline FDL MTrP & 1 & 0.857 & 0.857 & 1 & 1 & $.910(.771-.964)$ \\
\hline Rectus femoris MTrP & 1 & 0.875 & 0.643 & 1 & 0.875 & $.834(.628-.931)$ \\
\hline VM MTrP1 & 0.898 & 1 & 0.857 & 1 & 0.898 & $.872(.704-.947)$ \\
\hline VM MTrP2 & 0.857 & 0.875 & 1 & 0.773 & 0.857 & $.824(.637-.926)$ \\
\hline Vastus lateralis MTrP1 & 0.898 & 0.898 & 0.857 & 0.857 & 0.898 & $.919(.795-.968)$ \\
\hline Vastus lateralis MTrP2 & 0.783 & 0.886 & 0.780 & 0.780 & 0.894 & $.857(.673-.941)$ \\
\hline
\end{tabular}




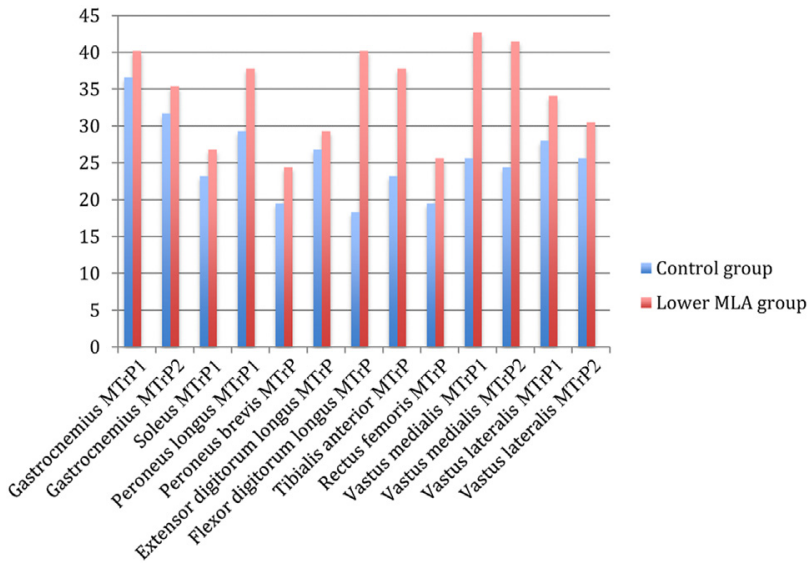

Fig 3 Prevalence (\%) of LTrPs in lower MLA and control groups. Statistically significant differences $(P<.05)$ are found in the TA, FDL, and VM.

controls. There are no studies that evaluated the prevalence of LTrPs in subjects with a lower MLA compared with controls. Mechanical disorders are related to the development of MTrPs. ${ }^{31,54}$ which include small hemi-pelvic or short upper arms. ${ }^{46}$ A lower MLA and/or the pronation of the subtalar joint can be either an activation or a perpetuation factor in several MTrPs, including PL, $\mathrm{PB}, \mathrm{FDL}, \mathrm{TP}$, and $\mathrm{VM},{ }^{46}$ and could be related to a lower limb length discrepancy or changes in muscle activity during gait. ${ }^{46}$

A statistically significant difference is found in the total number of LTrPs between both groups, which was higher in the lower MLA group $(4.46 \pm 4.10)$ than in the control group (3.32 \pm 3.24$)$. LTrPs are indeed prevalent in controls. Other authors have studied the prevalence of LTrPs in the lower limb muscles. Grieve $^{38}$ found in 220 asymptomatic subjects that the prevalence of LTrPs ranges from $19 \%$ to $30 \%$ in the gastrocnemius and from $16 \%$ to $21 \%$ in the soleus. Torres-Chica et al $^{55}$ found a similar number of LTrPs in controls $(4 \pm 1)$ as in subjects with postmeniscectomy pain $(4 \pm 4)$. In controls, the highest prevalence of LTrPs was found in the medial gastrocnemius $(58 \%-64 \%)$ and the lowest in the rectus femoris $(3 \%-6 \%)$. These findings suggest that LTrPs are common in subjects without pain. LTrPs are a potential source of disability, affecting the muscle function ${ }^{45}$ and range of movement, ${ }^{43}$ and can become ATrPs. ${ }^{56}$ To prevent these alterations, the evaluation and treatment of LTrPs could be necessary.

The prevalence of LTrPs in several injured subjects has been studied. In fact, LTrPs are frequent in lateral epicondylalgia, ${ }^{34}$ shoulder impingement, ${ }^{57}$ or tension-type headache. ${ }^{58}$ Regarding lower limb injuries, Roach et $\mathrm{al}^{59}$ found that subjects with patellofemoral pain have a high prevalence of LTrPs in the gluteus medius and quadratus lumborum. Torres-Chica ${ }^{55}$ evaluated the prevalence of MTrPs in subjects with postmeniscetomy pain who showed more ATrPs than did controls. Henry et al ${ }^{60}$ found that subjects waitlisted for total knee arthroplasty presented ATrPs in the knee muscles, including gastrocnemius, VM, and vastus lateralis. However, we did not find other studies that have evaluated the relation between the height of the MLA and the prevalence of LTrPs or ATrPs. Subjects with a lower MLA could develop more LTrPs because flat foot affects kinematics during gait. $^{21,30,61}$ These subjects showed a different electromyographic activity during gait. ${ }^{26}$ This can produce fatigue in the affected muscles, and muscle fatigue could be a cause of the presence of MTrPs. ${ }^{31}$
The lower MLA group has significantly more LTrPs than does the control group in all the muscles evaluated, which are statistically significant in the FDL, TA, and VM. This could be of clinical relevance. Thus, the prevalence of LTrPs in the FDL in the lower MLA group is twice that in the control group. Simons et $\mathrm{al}^{46}$ suggested that a lower MLA and foot pronation can be the causes of the development of MTrPs in the PL, PB, FDL, TP, and VM. In our study, statistically significant differences between the lower MLA group and the control group are evident in the TA, VM, and FDL, but not in the PL and PB. A possible cause of the development of LTrPs in the lower MLA group can be the muscular alterations presented during gait. The TA presents significantly greater electromyographic activity during both contact and stance phases, ${ }^{30,62}$ and its tendon is thicker in subjects with a lower MLA than in those with a normal MLA. ${ }^{63}$ These findings may be related to the increased demand of the TA to control the foot during the contact phase of gait in flat foot, ${ }^{63}$ which is responsible for decelerating ankle joint plantar flexion and/or resisting foot pronation. $^{64}$

No prevalence studies were found including FDL. The FDL in subjects with a lower MLA presented a larger cross-sectional area and thickness than did the FDL in subjects with a normal MLA. ${ }^{65}$ The FDL supported the MLA, ${ }^{66}$ and its hypertrophy can be related to the compensatory activity in supporting the MLA and producing supination in the ankle. ${ }^{65}$

The VM also showed more activity in subjects with a lower MLA, especially when the speed of gait increased. ${ }^{67}$ It could be related to the kinematic alterations produced by the decrease in the height of the MLA and foot pronation.

Although Simons ${ }^{46}$ suggested that a lower MLA and foot pronation could be the causes of the development of MTrPs in the PL and PB, we did not find a statistically significant difference with controls. The function of the PL and PB in supporting the MLA is less clear than the function in other muscles. ${ }^{65}$ Although the PL might be able to elevate the MLA through plantar flexion of the first metatarsal, it showed less electromyographic activity during the contact phase of gait. ${ }^{30,62}$ In addition, a smaller crosssectional area and thickness are found in the PL and PB in subjects with a lower MLA. ${ }^{65}$ Several causes of a lower activity of the PL have been found: the small volume and moment arm of the PL compared with the supinator muscles ${ }^{65}$ and lesser lateral instability in lower MLA requiring less PL activity. ${ }^{62}$

Other muscles that did not present statistically significant differences in the prevalence of LTrPs were the gastrocnemius, soleus, and extensor digitorum longus. The prevalence of LTrPs in the gastrocnemius and soleus in both controls and subjects with a lower MLA in the present study is similar to that in other studies. $^{38}$ The effect of the height of the MLA in the muscle activity of the gastrocnemius is not clear. Hunt and Smith ${ }^{30}$ found greater electromyographic activity of the gastrocnemius at the beginning of the stance phase but lesser at the end. In contrast, Murley et $\mathrm{al}^{62}$ found that the height of the MLA does not affect the electromyographic activity of the gastrocnemius.

LTrPs are common in the lower limb muscles in both subjects with a lower MLA and controls. The increase in the prevalence of LTrPs in subjects with a lower MLA, especially in the TA, FDL, and VM, where this prevalence could be of clinical importance, implies that the evaluation and control of the height of the MLA in the management of the myofascial pain syndrome may be necessary. Although LTrPs are not related to spontaneous pain, they can produce other symptoms, affecting movement 
Table 4 Prevalence of LTrPs and the specific diagnostic criteria

\begin{tabular}{|c|c|c|c|c|c|c|}
\hline Muscle & $\mathrm{LTrP}$ & Taut Band & Spot Tender & Jump Sign & Referred Pain & LTR \\
\hline \multicolumn{7}{|c|}{ Gastrocnemius MTrP1 } \\
\hline Control & $30(37)$ & $30(100)$ & $30(100)$ & $6(20)$ & $12(43)$ & $1(3)$ \\
\hline Lower MLA & $33(40)$ & $33(100)$ & $33(100)$ & $7(21)$ & $13(39)$ & $1(3)$ \\
\hline \multicolumn{7}{|c|}{ Gastrocnemius MTrP2 } \\
\hline Control & $26(32)$ & $26(100)$ & $26(100)$ & $5(19)$ & $11(42)$ & $1(4)$ \\
\hline Lower MLA & $29(35)$ & $29(100)$ & $29(100)$ & $6(21)$ & $13(45)$ & $1(4)$ \\
\hline \multicolumn{7}{|l|}{ Soleus MTrP1 } \\
\hline Control & $19(23)$ & $19(100)$ & $19(100)$ & $2(11)$ & $6(32)$ & 0 \\
\hline Lower MLA & $22(27)$ & $22(100)$ & $22(100)$ & $2(9)$ & $7(32)$ & 0 \\
\hline \multicolumn{7}{|l|}{ PL MTrP } \\
\hline Control & $24(29)$ & $24(100)$ & $24(100)$ & $5(21)$ & $9(38)$ & $1(4)$ \\
\hline Lower MLA & $31(38)$ & $31(100)$ & $31(100)$ & $6(19)$ & $10(32)$ & $1(3)$ \\
\hline \multicolumn{7}{|l|}{ PB MTrP } \\
\hline Control & $16(20)$ & $15(94)$ & $16(100)$ & $1(6)$ & $5(31)$ & 0 \\
\hline Lower MLA & $20(24)$ & $19(95)$ & $19(95)$ & $2(10)$ & $7(35)$ & 0 \\
\hline \multicolumn{7}{|c|}{ Extensor digitorum longus MTrP } \\
\hline Control & $22(27)$ & $22(100)$ & $22(100)$ & $4(18)$ & $7(32)$ & 0 \\
\hline Lower MLA & $24(29)$ & $24(100)$ & $23(96)$ & $4(17)$ & $7(29)$ & 0 \\
\hline \multicolumn{7}{|l|}{$\mathrm{FDL} M \operatorname{MrP} *$} \\
\hline Control & $15(18)$ & $15(100)$ & $14(93)$ & $1(7)$ & $5(33)$ & 0 \\
\hline Lower MLA & $33(40)$ & $32(97)$ & $32(97)$ & $1(3)$ & $11(33)$ & 0 \\
\hline \multicolumn{7}{|l|}{ TA MTrP* } \\
\hline Control & $19(23)$ & $19(100)$ & $19(100)$ & $3(16)$ & $8(42)$ & $1(5)$ \\
\hline Lower MLA & $31(38)$ & $31(100)$ & $31(100)$ & $4(13)$ & $12(39)$ & $1(3)$ \\
\hline \multicolumn{7}{|c|}{ Rectus femoris MTrP } \\
\hline Control & $16(20)$ & $16(100)$ & $16(100)$ & $1(6)$ & $5(31)$ & 0 \\
\hline Lower MLA & $21(26)$ & $21(100)$ & $21(100)$ & $1(5)$ & $7(33)$ & 0 \\
\hline \multicolumn{7}{|l|}{ VM MTrP1* } \\
\hline Control & $21(26)$ & $21(100)$ & $21(100)$ & $2(10)$ & $7(33)$ & $1(5)$ \\
\hline Lower MLA & $35(43)$ & $35(100)$ & $34(97)$ & $3(9)$ & $11(31)$ & $1(3)$ \\
\hline \multicolumn{7}{|l|}{ VM MTrP2* } \\
\hline Control & $20(24)$ & $20(100)$ & $19(95)$ & $3(15)$ & $7(35)$ & 0 \\
\hline Lower MLA & $34(42)$ & $34(100)$ & $34(100)$ & $6(18)$ & $13(38)$ & 0 \\
\hline \multicolumn{7}{|c|}{ Vastus lateralis MTrP1 } \\
\hline Control & $23(28)$ & $23(100)$ & $22(96)$ & $4(17)$ & $8(35)$ & $1(4)$ \\
\hline Lower MLA & $28(34)$ & $28(100)$ & $28(100)$ & $3(11)$ & $11(39)$ & $1(4)$ \\
\hline \multicolumn{7}{|c|}{ Vastus lateralis MTrP2 } \\
\hline Control & $21(26)$ & $20(95)$ & $21(100)$ & $3(14)$ & $8(38)$ & 0 \\
\hline Lower MLA & $25(31)$ & $24(96)$ & $25(100)$ & $4(16)$ & $9(36)$ & $1(4)$ \\
\hline
\end{tabular}

efficiency ${ }^{45}$ and can turn into ATrPs if the causes are not corrected. $^{31,33}$ Several authors have demonstrated that the control of the height of the MLA affected the electromyographic activity, decreasing the activity of the TA and $\mathrm{TP}^{68,69}$ and increasing the activity of the PL. ${ }^{26,70}$

\section{Study limitations}

Our study has potential limitations. First of all, we have evaluated only the presence of LTrPs in subjects without pain. A study evaluating the presence of ATrPs is necessary in the near future.

Second, the TP was not included in the study. The TP is one of the most important muscles supporting the MLA, ${ }^{66}$ and its dysfunction is a cause of flat foot. ${ }^{71}$ It is believed that the MLA in the flat foot undergoes greater loading than that in the normal foot, requiring greater work of the TP. ${ }^{62}$ The TP presents greater electromyographic activity, ${ }^{72}$ especially during the midstance and propulsion phases, in subjects with a lower MLA than in controls. ${ }^{62}$ We did not include the TP because it is a deep muscle, and direct palpation is not possible except across the soleus. ${ }^{46}$ This complicates the diagnosis of LTrPs, because spontaneous pain does not exist as in ATrPs.

Third, it is necessary to study the mechanisms involved in subjects with a lower MLA who showed a high prevalence of LTrPs in several lower limb muscles.

\section{Conclusions}

The reliability of the diagnosis of LTrPs was excellent in all the muscles evaluated. The taut band and tender spot showed 
excellent reliability, whereas the jump sign was the least reliable diagnostic criterion. The PPT also showed excellent reliability.

LTrPs are common in several lower limb muscles in both controls and subjects with a lower MLA. The decrease in the height of the MLA is associated with a higher prevalence of LTrPs, which is significant in the TA, FLD, and VM. A study of the height of the MLA may be necessary in the management of the myofascial pain syndrome in the lower limb.

\section{Suppliers}

a. GlaxoSmithKline.

b. Wagner Instruments.

c. IBM Corp.

\section{Keywords}

Lower extremity; Prevalence; Rehabilitation; Trigger points

\section{Corresponding author}

Juan C. Zuil-Escobar, PT, MSc, Department of Nursing and Physical Therapy, Faculty of Medicine, CEU San Pablo University, Ctra. Boadilla del Monte, km 5.300, 28668 Madrid, Spain.E-mail address: jczuil@ceu.es.

\section{References}

1. Xiong S, Goonetilleke RS, Witana CP, Weerasinghe TW, Au EY. Foot arch characterization: a review, a new metric, and a comparison. J Am Podiatr Med Assoc 2010;100:14-24.

2. Razeghi M, Batt ME. Foot type classification: a critical review of current methods. Gait Posture 2002;15:282-91.

3. Donatelli R. Normal biomechanics of the foot and ankle. Orthop Sports Phys Ther 1985;7:91-5.

4. Tiberio D. The effect of excessive subtalar joint pronation on patellofemoral mechanics: a theoretical model. J Orthop Sports Phys Ther 1987;9:160-5.

5. Nguyen AD, Shultz SJ. Identifying relationships among lower extremity alignment characteristics. J Athl Train 2009;44:511-8.

6. Shultz SJ, Nguyen AD, Levine BJ. The relationship between lower extremity alignment characteristics and anterior knee joint laxity. Sports Health 2009;1:54-60.

7. Shultz SJ, Dudley WN, Kong Y. Identifying multiplanar knee laxity profiles and associated physical characteristics. J Athl Train 2012;47: 159-69.

8. Pinto RZ, Souza TR, Trede RG, Kirkwood RN, Figueiredo EM, Fonseca ST. Bilateral and unilateral increases in calcaneal eversion affect pelvic alignment in standing position. Man Ther 2008;13: 513-9.

9. Shultz SJ, Carcia CR, Gasnneder BM, Perrin DH. The independent and interactive effects of navicular drop and quadriceps angle on neuromuscular responses to a weight-bearing perturbation. J Ath Train 2006;41:251-9.

10. Barton CJ, Bonanno D, Levinger P, Menz HB. Foot and ankle characteristics in patellofemoral pain syndrome: a case control and reliability study. J Orthop Sports Phys Ther 2010;40:286-96.

11. Williams DS, McClay IS. Measurements used to characterize the foot and the medial longitudinal arch: reliability and validity. Phys Ther 2000;80:864-71.

12. Williams DS III, McClay IS, Hamill J. Arch structure and injury patterns in runners. Clin Biomech (Bristol, Avon) 2001;16:341-7.
13. Moen MH, Bongers T, Bakker EW, et al. Risk factors and prognostic indicators for medial tibial stress syndrome. Scand J Med Sci 2012; 22:34-9.

14. Newman P, Witchalls J, Waddington G, Adams R. Risk factors associated with medial tibial stress syndrome in runners: a systematic review and meta-analysis. Open Access J Sports Med 2013;4:229-41.

15. Mølgaard C, Rathleff MS, Simonsen O. Patellofemoral pain syndrome and its association with hip, ankle, and foot function in 16- to 18-year-old high school students: a single-blind case-control study. J Am Podiatr Med Assoc 2011;101:215-22.

16. Boling MC, Padua DA, Marshall SW, Guskiewicz K, Pyne S, Beutler A. A prospective investigation of biomechanical risk factors for patellofemoral pain syndrome: the Joint Undertaking to Monitor and Prevent ACL Injury (JUMP-ACL) cohort. Am J Sports Med 2009;37:2108-16.

17. Loudon JK, Jenkins W, Loudon KL. The relationship between static posture and ACL injury in female athletes. J Orthop Sports Phys Ther 1996;24:91-7.

18. Woodford-Rogers B, Cyphert L, Denegar CR. Risk factors for anterior cruciate ligament injury in high school and college athletes. J Athl Train 1994;29:343-6.

19. Hertel J, Dorfman JH, Braham RA. Lower extremity malalignments and anterior cruciate ligament injury history. J Sports Sci Med 2004; 3:220-5.

20. Reilly K, Barker K, Shamley D, Newman M, Oskrochi GR, Sandall S. The role of foot and ankle assessment of patients with lower limb osteoarthritis. Physiotherapy 2009;95:164-9.

21. Levinger P, Menz HB, Fotoohabadi MR, Feller JA, Bartlett JR, Bergman NR. Foot posture in people with medial compartment knee osteoarthritis. J Foot Ankle Res 2010;3:29.

22. Brantingham JW, Lee Gilbert J, Shaik J, Globe G. Sagittal plane blockage of the foot, ankle and hallux and foot alignment-prevalence and association with low back pain. J Chiropr Med 2006;5: 123-7.

23. Cote KP, Brunett ME, Gansneder BM, Shultz SJ. Effects of pronated and supinated foot postures on static and dynamic postural stability. J Ath Train 2005;40:41-6.

24. Jonely H, Brismée JM, Sizer PS Jr, James CR. Relationships between clinical measures of static foot posture and plantar pressure during static standing and walking. Clin Biomech (Bristol, Avon) 2011;26: 873-9.

25. Denyer JR, Hewitt NL, Mitchell AC. Foot structure and muscle reaction time to a simulated ankle sprain. J Athl Train 2013;48: 326-30.

26. Murley GS, Landorf KB, Menz HB, Bird AR. Effect of foot posture, foot orthoses and footwear on lower limb muscle activity during walking and running: a systematic review. Gait Posture 2009;29: $172-87$.

27. Telfer S, Abbott M, Steultjens M, Rafferty D, Woodburn J. Doseresponse effects of customised foot orthoses on lower limb muscle activity and plantar pressures in pronated foot type. Gait Posture 2013;38:443-9.

28. Shultz SJ, Nguyen AD, Windley TC, Kulas AS, Botic TL, Beynnon BD. Intratester and intertester reliability of clinical measures of lower extremity anatomic characteristics: implications for multicenter studies. Clin J Sport Med 2006;16:155-61.

29. Snook AG. The relationship between excessive pronation as measured by navicular drop and isokinetic strength of the ankle musculature. Foot Ankle Int 2001;22:234-40.

30. Hunt AE, Smith RM. Mechanics and control of the flat versus normal foot during the stance phase of walking. Clin Biomech (Bristol, Avon) 2004;19:391-7.

31. Simons DG, Travell J, Simons L. Myofascial pain and dysfunction: the trigger point manual. Vol 1. 2nd ed. Baltimore: William \& Wilkins; 1999.

32. Simons DG. Review of enigmatic MTrPs as a common cause of enigmatic musculoskeletal pain and dysfunction. J Electromyogr Kinesiol 2004;14:95-107. 
33. Li LT, Ge HY, Yue SW, Arendt-Nielsen L. Nociceptive and nonnociceptive hypersensitivity at latent myofascial trigger points. Clin J Pain 2009;25:132-7.

34. Fernández-Carnero J, Fernández-de-las-Peñas C, de la LlaveRincón AI, Ge HY, Arendt-Nielsen L. Prevalence of and referred pain from myofascial trigger points in the forearm muscles in patients with lateral epicondylalgia. Clin J Pain 2007;23:353-60.

35. Bron C, Dommerholt J, Stegenga B, Wensing M, Oostendorp RA. High prevalence of shoulder girdle muscles with myofascial trigger points in patients with shoulder pain. BMC Musculoskelet Disord 2011;12:139.

36. Sola AE, Rodenberger MI, Gettys BB. Incidence of hypersensitive areas in posterior shoulder muscles. Am J Phys Med 1955;34:585-90.

37. Lucas KR, Rich PA, Polus BI. How common are latent myofascial trigger points in the scapular positioning muscles? J Musculoskelet Pain 2008;16:279-86.

38. Grieve R, Barnett S, Coghill N, Cramp F. The prevalence of latent myofascial trigger points and diagnostic criteria of the triceps surae and upper trapezius: a cross sectional study. Physiotherapy 2013;99: 278-84.

39. Shah JP, Phillips TM, Danoff JV, Gerber LH. An in vivo microanalytical technique for measuring the local biochemical milieu of human skeletal muscle. J Appl Physiol 2005;99:1977-84.

40. Ge HY, Zhang Y, Boudreau S, Yue SW, Arendt-Nielsen L. Induction of muscle cramps by nociceptive stimulation of latent myofascial trigger points. Exp Brain Res 2008;187:623-9.

41. Ge HY, Monterde S, Graven-Nielsen T, Arendt-Nielsen L. Latent myofascial trigger points are associated with an increased intramuscular electromyographic activity during synergistic muscle activation. J Pain 2014;15:181-7.

42. Ibarra JM, Ge HY, Wang C, Martínez Vizcaíno V, Graven-Nielsen T, Arendt-Nielsen L. Latent myofascial trigger points are associated with an increased antagonistic muscle activity during agonist muscle contraction. J Pain 2011;12:1282-8.

43. Ge HY, Arendt-Nielsen L. Latent myofascial trigger points. Curr Pain Headache Rep 2011;15:386-92.

44. Sikdar S, Shah JP, Gebreab T, et al. Novel applications of ultrasound technology to visualize and characterize myofascial trigger points and surrounding soft tissue. Arch Phys Med Rehabil 2009;90: 1829-38.

45. Lucas KR, Polus BI, Rich PA. Latent myofascial trigger points: their effects on muscle activation and movement efficiency. J Bodyw Mov Ther 2004;8:160-6.

46. Simons DG, Travell J, Simons L. Myofascial pain and dysfunction: the trigger point manual. Vol 2. 2nd ed. Baltimore: William \& Wilkins; 1999 .

47. Nakhaee Z, Rahimi A, Abaee M, Rezasoltani A, Kalantari KK. The relationship between the height of the medial longitudinal arch (MLA) and the ankle and knee injuries in professional runners. Foot 2008:18:84-90.

48. Hargrave MD, Carcia CR, Gansneder BM, Shultz SJ. Subtalar pronation does not influence impact forces or rate of loading during a single-leg landing. J Athl Train 2003;38:18-23.

49. Hoffman M, Schrader J, Applegate T, Koceja D. Unilateral postural control of the functionally dominant and nondominant extremities of healthy subjects. J Athl Train 1998:33:319-22.

50. Brody D. Techniques in the evaluation and treatment of the injured runner. Orthop Clin North Am 1982;13:542-58.

51. Fischer AA. Reliability of the pressure algometer as a measure of myofascial trigger point sensitivity. Pain 1987;23:411-4.

52. Fleiss J. The design and analysis of clinical experiments. New York: Wiley; 1999.

53. Bron C, Franssen J, Wensing M, Oostendorp RA. Interrater reliability of palpation of myofascial trigger points in three shoulder muscles. J Man Manip Ther 2007;15:203-15.
54. Edwards J. The importance of postural habits in perpetuating myofascial trigger point pain. Acupunct Med 2005;23:77-82.

55. Torres-Chica B, Núñez-Samper-Pizarroso C, Ortega-Santiago R, et al. Trigger points and pressure pain hypersensitivity in people with post-meniscectomy pain. Clin J Pain 2015;31:265-72.

56. Hong CZ, Simons DG. Pathophysiologic and electrophysiologic mechanisms of myofascial trigger points. Arch Phys Med Rehabil 1998;79:863-72

57. Hidalgo-Lozano A, Fernández-de-las-Peñas C, Alonso Blanco C, Ge HY, Arendt-Nielsen L, Arroyo-Morales M. Muscle trigger points and pressure pain hyperalgesia in the shoulder muscles in patients with unilateral shoulder impingement: a blinded, controlled study. Exp Brain Res 2010;202:915-25.

58. Fernández-de-las-Peñas $\mathrm{C}, \mathrm{Ge} \quad \mathrm{H}$, Arendt-Nielsen L, Cuadrado ML, Pareja JA. The local and referred pain from myofascial trigger points in the temporalis muscle contributes to pain profile in chronic tension-type headache. Clin J Pain 2007; 23:786-92.

59. Roach S, Sorensen E, Headley B, San Juan JG. Prevalence of myofascial trigger points in the hip in patellofemoral pain. Arch Phys Med Rehabil 2013;94:522-6.

60. Henry R, Cahill CM, Wood G, et al. Myofascial pain in patients waitilisted for total knee arthroplasty. Pain Res Manage 2012;17: 321-7.

61. Kim MK, Lee YS. A three-dimensional gait analysis of people with flat arched feet on an ascending slope. J Phys Ther Sci 2014;26: 1437-40.

62. Murley GS, Menz HB, Landorf KB. Foot posture influences the electromyographic activity of selected lower limb muscles during gait. J Foot Ankle Res 2009;2:35.

63. Murley GS, Tan JM, Edwards RM, De Luca J, Munteanu SE, Cook JL. Foot posture is associated with morphometry of the peroneus longus muscle, tibialis anterior tendon, and Achilles tendon. Scand J Med Sci Sports 2014;24:535-41.

64. Hunt AE, Smith RM, Torode M. Extrinsic muscle activity, foot motion and ankle joint moments during the stance phase of walking. Foot Ankle Int 2001;22:31-41.

65. Angin S, Crofts G, Mickle KJ, Nester CJ. Ultrasound evaluation of foot muscles and plantar fascia in pes planus. Gait Posture 2014;40: 48-52.

66. Thordarson D, Schmotzer H, Chon J, Peters J. Dynamic support of the human longitudinal arch: a biomechanical evaluation. Clin Orthop 1995;316:165-72.

67. Lee CR, Kim MK. The effects on muscle activation of flatfoot during gait according to the velocity on an ascending slope. J Phys Ther Sci 2014;26:675-7.

68. Franettovich M, Chapman A, Vicenzino B. Tape that increases medial longitudinal arch height also reduces leg muscle activity: a preliminary study. Med Sci Sports Exerc 2008;40: 593-600.

69. Franettovich MM, Murley GS, David BS, Bird AR. A comparison of augmented low-Dye taping and ankle bracing on lower limb muscle activity during walking in adults with flat-arched foot posture. J Sci Med Sport 2012;15:8-13.

70. Murley GS, Bird AR. The effect of three levels of foot orthotic wedging on the surface electromyographic activity of selected lower limb muscles during gait. Clin Biomech (Bristol, Avon) 2006;21: 1074-80.

71. Arai K, Ringleb SI, Zhao KD, Berglund LJ, Kitaoka HB, Kaufman KR. The effect of flatfoot deformity and tendon loading on the work of friction measured in the posterior tibial tendon. Clin Biomech 2007;22:592-8.

72. Keenan MA, Peabody TD, Gronley JK, Perry J. Valgus deformities of the feet and characteristics of gait in patients who have rheumatoid arthritis. J Bone Joint Surg Am 1991;73:237-47. 